\title{
Nanomodified constructional fiber-reinforced concrete
}

\author{
Vladimir Perfilov ${ }^{1, *}$, and Viktoriya Gabova ${ }^{1}$ \\ ${ }^{1}$ Volgograd State Technical University, Oil and Gas Constructions Department, Avenue V.I. Lenin, 28, 400005, Volgograd, Russia
}

\begin{abstract}
Nanotechnology of receipt of the high-strength fiber-reinforced concrete which don't have analogs, using nanocarbon additives, the modified gel on a structure nanolevel, applied knitting is developed for improvement of physicomechanical properties on micro and nanolevel that allowed to create concrete with exceptional properties.
\end{abstract}

\section{Introduction}

The researches conducted for the last years convincingly show that fiber reinforcing improves mechanical characteristics of concrete, contributes resistance of concrete to impact of aggressive environment, allows to reduce thickness of designs and significantly to reduce or to completely exclude an armature expense. Thus, favorable conditions for decrease of material capacity and labor input of construction are created. However so far the use of fiber-reinforced concrete is practically absent because of high cost of steel fiber and lack of special technology of its stacking. One of the main reasons of insufficient application of fiber-reinforced concrete is lack of understanding by industrial organizations of great advantages of their application, and also lack of science-based regulating documentation. For the solution of this and other scientific problems connected with rational selecting of components of fiberreinforced concrete the offered project is directed.

Fiber-reinforced concrete, being heterogeneous material, is characterized by microstructure of the cement gel, and also macrostructure caused by interaction knitting and fillers. For increase of durability and crack resistance of concrete at the macrolevel use of basalt fiber fibers blocking development of cracks is perspective [1-12].

Proving prospects of application as the dispersereinforced component of basalt fiber fiber-reinforced concrete is necessary to pay special attention to studying of physicomechanical characteristics of basalt fiberreinforced concrete. Having studied the principles of structurization of this type of concrete is possible to improve, influencing at different levels, structure of cement and sand matrix.

\section{Main part}

The disperse-reinforced concrete and solution represents the cement and basalt composite having the increased durability of compressed cross-sections bent and also the stretched elements of designs.
Basalt fiber contributes at stage of mixing of components to formation rheological of the homogeneous mixture possessing high rates of plasticity, and also which is characterized by its homogeneity. Considering process of structure formation at the microscopic level between the cement stone and basalt fiber in the contact zone "basalt fiber - cement matrix", there are new growths which arise owing to interaction of hydroxide of calcium of portland cement and oxide of silicon of basalt fiber. It is known that basalt fiber is characterized by the high degree of adhesion to the cement matrix. For this reason the field of engagement of fiber and matrix rather close, providing full contact of surfaces, excepting cracks and gaps. At the time of hardening, received basalt fiber-reinforced concrete, has three-dimensional the reinforced microstructure of cement composite with more evenly redistributed efforts arising in concrete blocking formation and development of cracks.

Thus, the basalt fiber reduces shrinkage and cracking at the microlevel, increasing ability of concrete matrix to deformation, excepting destruction during the shrinkage, contributing conservation of internal energy of concrete. During hardening of concrete and its shrinkage, the basalt fiber as if connects edges of cracks, reducing thereby risk of fracture.

Besides disperse reinforcement the modifying components also exert different impact on microscopic level. Practice shows that change of properties for purpose of improvement of quality of concrete composites is impossible without directional regulation of his formation. It is reached by introduction to mix of chemical additives.

Formation of microstructure of cement stone on which depend the main physicomechanical properties of concrete begins with the supramolecular level of dispersion of particles of size $3-5 \cdot 10^{-9} \mathrm{~m}$ (3-5 nanometers). The calcium hydrosilicates which are formed as a result of interaction of the cement knitting with water during an initial stage of hydration at the supramolecular level have size of elementary germs of new crystalline phase to 3 nanometers. The defects of

\footnotetext{
* Corresponding author: vladimirperfilov@mail.ru
} 
structure in the form of dislocations having the similar sizes also begin to be formed at this stage of formation of cement stone.

Now researchers with mistrust treat of use of nanocarbon additives in solutions and concrete. It, apparently, is connected with the fact that it is difficult to present how miserable dosages of nanoadditives can be subsequently the centers of crystallization of new growths of cement stone.

The following can serve as an explanation of positive influence of nanoadditives on physicomechanical properties of solutions and concrete.

It is known that when using plasticizers in amounts of nanoadditives, commensurable with dosage, there is their full dissolution in mixing water which contributes to adsorption of molecules of additive on surface of components of mixture with formation of the thinnest layer increasing wettability of solution. As a result, the water-cement relation by increasing the mobility of mixture decreases and conditions for homogeneous distribution of all components of solutions and concrete improve. It, in turn, contributes formation of dense homogeneous structure of the hardened concrete with improved physicomechanical characteristics. However the plasticizing water-soluble additives directly don't participate in interaction with hydrosilicates of new growths of cement stone. Their role consists only in improvement (acceleration) of conditions of formation of microcrystalline structure of cement stone.

It is possible to strengthen gel structure of cement stone on nanolevel by use of the multilayered nanohallow carbon tubes allowing to significantly change physicomechanical parameters. It is connected with the fact that nanotubes are directly involved in processes of crystallization of cement stone due to adhesion and directed microstructural formation of hydrosilicates. Nanotubes on which surface, including internal cavities, there is adhesion and subsequent interaction of products of cement hydration have hundreds of times greater durability in comparison with cement hydrosilicates. As a result the strongest particles of carbon nanoadditives become bases (centers) of crystallization of new growths of cement stone that leads to microhardening of structure and significant improvement of physicomechanical properties of the hardened composite materials. Nanotubes are material with a huge number of loosely coupled valent electrons, besides, that the atomic framework has a high stability. For this reason nanoadditives, being on limit of the section of phases in the polarized condition, it adgezirutsya adgesiruta and directed forms crystalline hydrates. Formation of the fibrillar microstructure allowing to increase physicomechanical properties of a bazalt fiber-reinforced concrete on micro and a nanolevel is result of nanomodification [13-28].

For a greater hardening of structure appropriate use of various high-strength fiber fibers on which surface products of hydration of cement stone together with nanoadditives will also adhesivity is reasonable.

Nanotechnology of receipt of the high-strength fiberreinforced concrete which don't have analogs, using nanocarbon additives, the modified gel on a structure nanolevel, applied knitting is developed for improvement of physicomechanical properties on micro and nanolevel that allowed to create concrete with exceptional properties [14,15].

Nanotubes represent hollow cylindrical tubes from one or several atoms of carbon. The multilayered nanotubes of "Taunit" received in LLC "Nanotechcenter" of the Tambov state technical university are of the greatest interest.

For more complete dispergating of water-insoluble nanocoal family of additives application of the known low-resourceful mixing installations is insufficient. Now the most effective are ultrasonic devices with a frequency from 20 to $26 \mathrm{kHz}$, for example, ultrasonic dispergators of the USD brand or ultrasonic bathtubs. Application of the above-stated installations allows the most complete distribution of particles of nanocarbon additives on all amount of water of mixing water. The advantage of such technology is also long stability of the received suspension, up to two weeks.

Thus, mixing water activated by nanocarbon additives by means of ultrasonic hashing possesses a high reactionary capability for the most complete interaction with minerals of cement and receipt of dense and strong microstructure of solutions and concretes.

In researches nanostructuring of cement stone was made by means of introduction in solution of carbon nanotubes "Taunit" representing cylindrical tubes from one or several atoms of carbon. Outer diameter of nanotube is $15-40$ nanometers; internal diameter is $3-$ 8 nanometers, and length - to several microns. The main advantages of nanotubes is their small dosage in concrete constituting thousand and ten-thousand shares of percent from weight knitting at durability to several GPa that in hundreds times more of durability of hydrosilicates.

Thus, result of purposeful influence on regulation of processes of structurization on macro, micro and nanolevels is receipt of the constructional fiberreinforced concrete possessing improved strength characteristics, crack resistance, frost resistance and other considerable higher operational properties.

Task of scientific research is the increase of efficiency of process of receipt of the modified fiberreinforced concrete mixture directed to increase on its durability at compression and stretching in case of bend due to use of the components hardening the structure of fiber-reinforced concrete on micro and nanolevels.

The purpose of this stage of researches was studying of influence of "Taunit" nanoadditive on properties of fiber-reinforced concrete mixture and improved fiberreinforced concrete. As the modifying additives used carbon "Taunit" nanomodified received in LLC "Nanotechcenter" of the Tambov state technical university.

For the purpose of studying of influence of additives preliminary experiments were made on the basis of cement and sand mixture of structure cement:sand $=1: 2$ prepared in a spherical cup within 5 minutes for avoidance of " false setting" of portland cement.

As initial materials for production of samples of 40x40x160 mm the portland cement of production of CJSC "Oskolcement" of the PTs M500 D0-N brand, 
sand of CJSC "Orlovsky sand pit" of the Volgograd region, basalt microprofile of production of the LLC NPO "Vulkan company" in number of $1,4 \mathrm{~kg} / \mathrm{m}^{3}$ was used. Nanoadditive was entered in percentage terms from the mass of cement together with mixing water.

Complexity of production of solution with "Taunit" additive is connected with the fact that carbon nanotubes are insoluble in water. Therefore preparation of solution of "Taunit" nanoadditive was performed by means of ultrasonic dispergator of UZD1-0.1/22 with a frequency of $22-26 \mathrm{kHz}$ within 30 seconds. Formation of samples was made on the laboratory vibroplatform.

Determination of durability of control samples of solution was carried out at the age of 28 days according to GOST 10180 with use of the hydraulic testing machine of the "TECNOTEST company" of the KD 150-R15 brand with availability of the second channel with the device C 362/FN. Therefore received indicators on durability on compression and on stretching in case of bend.

Results of testing, the hardened samples from equally mobile of solution mixes are provided in the table.

The analysis of results of testing showed that introduction in mix of "Taunit" nanoadditive promotes increase in durability at compression at $56,44 \%$ and at stretching in case of bend for $74,1 \%$ in comparison with samples without additive in case of identical mobility of solution mix (see structure No. 5).

Table 1. Influence of "Taunit" additive on properties of finegrained fiber-reinforced concrete

\begin{tabular}{|c|c|c|c|c|}
\hline \multirow{2}{*}{$\begin{array}{c}\text { № } \\
\text { structure }\end{array}$} & \multirow[b]{2}{*}{$\begin{array}{l}\text { Amount } \\
\text { of } \\
\text { "Taunit" } \\
\text { additive } \\
\text { of the } \\
\text { mass of } \\
\text { cement }\end{array}$} & \multirow{2}{*}{$\begin{array}{c}\text { Spread } \\
\text { of cone, } \\
\text { mm }\end{array}$} & \multicolumn{2}{|c|}{ Durability, MPa } \\
\hline & & & bend & compression \\
\hline 1 & 0 & 107 & 2,7 & 42,86 \\
\hline 2 & 0,001 & 110 & 2,93 & 58,37 \\
\hline 3 & 0,005 & 111 & 4,2 & 60,17 \\
\hline 4 & 0,01 & 108 & 4,3 & 62,11 \\
\hline 5 & 0,05 & 108 & 4,7 & 67,05 \\
\hline 6 & 0,1 & 110 & 3,3 & 66,35 \\
\hline
\end{tabular}

\section{Conclusions}

By results of scientific research the computer program for matching of structure of fiber-reinforced concrete with nanoadditives is developed [29].

The new documentation including prescription structures of fiber-reinforced concrete using original designs of fibers, the nanodimensional complex additives allowing to modify gel (on nanolevel) a microstructure of the applied knitting is developed. Recommendations about manufacturing techniques of products on the basis of developed structures of fiberreinforced concrete are made. For practical application of new structures of fiber-reinforced concrete at the entities of the construction industry, and also in monolithic construction Technical conditions were developed [30]. They extend to the constructional heavy structural fiber-reinforced concrete with reinforcer from fiber "Mixarm" having the following subjects to application: monolithic construction, coverings of industrial floors, roads and airfields, tunnel constructions, bank vaults, pipelines, railway cross ties, piles, sidewalk coverings, wall panels, panels of overlapping and covering, tile and many other construction products and designs.

\section{References}

1. V.A. Perfilov, Fine-grained fiber-reinforced concrete, Monograph. Ministry of science and education of the Russian Federation. Volgograd state university of architecture and civil engineering, Volgograd: VSUACE, 126 p. (2015)

2. V.A. Perfilov, D.V. Oreshkin, M.O. Zubova, D.L. Neizvestnyj, I.G. Lukina, A.N. Chebotayev, Ballasting of underwater pipelines using a basalt fiber and boring slime, Construction of oil and gas wells by land and by sea, No. 11. Pp. 40-41 (2012)

3. D.V. Oreshkin, A.N. Chebotaev, V.A. Perfilov, Disposal of drilling sludge in the production of bulding materials, Procedia Engineering, T.11. Pp. 607-611 (2015)

4. V.A. Perfilov, D.V. Oreshkin, D.Y. Zemlyanushnov, Concrete strength and crack resistance control, Procedia Engineering 2. Cep. "2nd International Conference on Industrial Engineering, ICIE 2016", Pp. 1474-1478 (2016)

5. V.A. Perfilov, D.V. Oreshkin, V.S. Semenov, Environmentaliy safe mortar and grouting solutions with hollow glass microspheres, Procedia Engineering 2. "2nd International Conference on Industrial Engineering, ICIE 2016", Pp. 1479-1484 (2016)

6. V.A. Perfilov, A.V. Kotlyarevskaya, U.V. Kanavets, Influence of microreinforcing fibres and plasticizing additives on properties of fine-grained concrete, Bulletin of Volgograd State University of Architecture and Civil Engineering. Series: Civil Engineering and Architecture, Iss. 44 (63), P. 2. Pp. 111-118 (2016)

7. V.A. Perfilov, M.O. Zubova, The influence of superplasticizers on the property is fibrous concrete, Internet-Vestnik VolgGASU, No. 1(37), paper 11 (2015).

8. V.A. Perfilov, M.O. Zubova, Fine basalt fibre concrete, Bulletin of Volgograd State University of Architecture and Civil Engineering. Series: Civil Engineering and Architecture, Iss. 38(57), pp. 85-93 (2014)

9. V.A. Perfilov, M.O. Zubova, Basalt fiber fiber as main component of dispersed fibrous reinforcement concrete, Bulletin of the Donbass national academy of construction and architecture, No. 3 (101), Pp. 146-148 (2013) 
10. V.A. Perfilov, M.O. Zubova, D.L. Neizvestnyj, Fiber-reinforced concrete with basalt fillers and superplasticizers, Reliability and durability of construction materials, designs and foundations of the bases. Materials of the 6th International sciencetechnical conference. Volgograd, VSUACE, Pp. 248-250 (2011)

11. V.A. Perfilov, M.O. Zubova, D.L. Neizvestnyj, Application of basalt fibers and the modifying additive for increase in strength characteristics of heavy concrete, News of higher educational institutions. Construction, No.12, Pp. 46-49 (2011)

12. V.A. Perfilov, A.V. Atkina, O.A. Kusmartseva, Application of the components modifying the microreinforcing for increase in durability of cellular materials, News of higher educational institutions. Construction, No. 9, Pp. 11-14 (2010)

13. V.A. Perfilov, A.V. Atkina, O.A. Kusmartseva, U.V. Kanavets. Fiber-reinforced concrete with macroreinforces and nanoadditives, Social and economic and technological problems of development of a construction complex of the region. Science. Practice. Education. Materials III of the All-Russian scientific and technical conference, Pp. 236-238 (2009)

14. V.A. Perfilov, U,V, Alatortseva, A.A. Tyurin, Fiber-reinforced concrete of the accelerated curing. News of higher education institutions. Construction. Novosibirsk, No.1, Pp. 48-51 (2009)

15. V.A. Perfilov, U.V. Alatortseva, M.I. Dmitruk, I.L. Zhoga, Application of the modyfying nanoadditives for increase in durability of fiber-reinforced concrete, News of higher education institutions, Construction. Novosibirsk, No. 8, Pp. 17-19 (2009)

16. B.V. Gusev, Application of nanotechnologies and nanomaterials in construction: opinions of experts, Construction: new technologies - the new equipment, No. 1, Pp. 17-28 (2012)

17. V.R. Falikman, Nanomaterialy and nanotechnologies in modern concrete. Industrial and civil engineering, No. 1, Pp. 31-34 (2013)

18. M.E. Yudovich, A.N. Ponomarev, Nanomodification of plasticizers, regulation of their properties and strength characteristics of cast concrete.. Stroyprofil, No. 6, Pp. 49-51 (2007)

19. U.V. Alatortseva, Fiber-reinforced concrete based on nanostructural knitting.. Actual problems in construction and architecture. Education. Science. Proceedings of the 66th All-Russian scientifictechnical conference on the results of the research University in 2008. Samara: SSUABCE, Pp. 209210 (2009)

20. M. Vauchsky, Nanomodification of concrete - the absolute reality. Construction: new technologies, new equipment, No. 2, Pp. 47-52 (2009)

21. A.I. Vakhmistrov, V.I. Morozov, Yu.V. Pukharenko, A.N. Dmitriev, U.H. Magdeev,
Effective fiber-reinforced materials and products for construction, Industrial and civil engineering, No. 10, Pp. 43-44 (2007)

22. B.V. Gusev, Development of nanoscience and nanotechnologies. Industrial and civil engineering, No. 4, Pp. 45-46 (2007)

23. A.S. Korolev. Fine-grained concrete with nanoadditives of synthetic zeolite, Concrete and reinforced concrete, No. 6, Pp. 13-15 (2008)

24. V.A. Perfilov, U.V. Alatortseva, Constructional fiber-reinforced concrete with the use of modifying nanoadditives, Materials of the Second International forum on nanotechnologies on October 6-8, 2009 Moscow: Rusnanotech Group, Pp. 374-375 (2009)

25. V.A. Perfilov, U.V. Alatortseva, A.V. Atkina, O.A. Kusmantseva, The nanomodified structure of the knitting fiber-reinforced concrete, Nanotechnologies and nanomaterials: current state and prospects of development in conditions of Volgograd region: materials of the all-Russian scientific-technical conference, Volgograd: Volgograd state university, Pp. 373-380 (2009)

26. V.A. Perfilov, U.V. Alatortseva, A.V. Atkina, Fiber-reinforeced concretes with the use of modifying nanoadditives, Materials of the International week of construction materials devoted to the 65 anniversary of formation of construction and technological faculty of MGSU. - Moscow: MGSU, Pp. 105-110 (2009)

27. Yu.V. Pukharenko, Modern state and prospects of application fullerenic of nanostructures in cement compositions, Siberian industrialist No.3, Pp.30-31 (2008)

28. A.A. Smolikov, Concrete reinforced by nanofibers. Concrete and reinforced concrete, No. 4, Pp. 8-9 (2009)

29. V.A. Perfilov, S.P. Mityaev, Calculation of fiberreinforced concrete with nanoadditive. from 29.04.2009. The Certificate on the state registration of the computer program. No. 2009612195

30. V.A. Perfilov, U.V. Alatortseva, Fiber-reinforced concrete mixture with hardener from fiber "Mixarm" and nanoadditives", Technical conditions of TC of 574510-002-02068077-2008. 